\title{
Imagens constituintes: um exercício de análise de (contra)discurso
}

Alexandre Almeida Barbalho

Doutor em Comunicação e Cultura Contemporâneas pela UFBA - Universidade Federal da Bahia. Professor dos PPGS em Comunicação Social da UFC - Universidade Federal do Ceará, e em Politicas Públicas e Sociedade da UECE - Universidade Estadual do Ceará.

E-mail: alexandrebarbalho@hotmail.com

Resumo: Este artigo discute o programa NoAR, realizado por jovens das classes populares de Fortaleza e veiculado na TV pública do Estado do Ceará. As questões que norteiam a reflexão são as possibilidades de elaboração de um contradiscurso que escape à ordem discursiva a partir das práticas constituintes que esses jovens estabelecem em suas vidas cotidianas.

Palavras-chave: discurso, minoria, ordem, contraordem, imagem.
Abstract: This article discusses the program NoAR made by young persons of the popular classes of Fortaleza and conveyed in the public TV of the Ceará state. The questions that orientate the reflection are the means of preparation of a counter-speech that leak to the discursive order from the constituent practices that these young persons establish in their daily lives.

Keywords: speech, minority, order, counterorder, image.

Aprendemos com Michel Foucault que o discurso tem uma ordem ${ }^{1}$. O que implica determinar as condições de sua existência, fixar seus limites, correlacioná-lo com outros discursos e, por fim, mostrar o que excluem.

O enunciado de um discurso é da ordem do acontecimento, mas um acontecimento esquisito, pois não significa aleatoriedade, uma vez que traz consigo uma existência anterior. E depois de seu surgimento está sujeito à repetição, à transformação e à reativação. Por fim, os enunciados, além de estarem ligados ao contexto de sua criação e ao que provoca, também se relacionam aos discursos que os precedem e àqueles que os seguirão.

$\mathrm{Na}$ sua aula inaugural no Collège de France, Foucault expõe de forma mais didática a ordem do discurso - ordem que procura controlá-lo através de vários procedimentos no intuito de "conjurar seus poderes e perigos, dominar seu acontecimento aleatório, esquivar sua pesada e temível materialidade" ${ }^{2}$.

O primeiro procedimento é o de exclusão que opera por meio da interdição - proibições que se colocam ao discurso e que recaem sobre o que se fala (tabu do objeto); sobre como se fala (ritual da circunstância);

Recebido: 25.03 .2008

Aprovado: 15.07 .2008

1. FOUCAULT, Michel. A arqueologia do saber. Rio de Janeiro: Forense Universitária, 2002.

2. Id. A ordem do discurso. São Paulo: Loyola, 1998. p. 9. 
e sobre quem fala (direito exclusivo de fala). Outra forma de exclusão é a separação ou rejeição. Uma outra é a definição e a oposição do verdadeiro e do falso e a vontade de verdade.

Os procedimentos de exclusão, expostos anteriormente, são formas de controle e delimitação do discurso que se exercem do exterior e se relacionam ao jogo entre o poder e o desejo. Mas há os procedimentos internos, quando os discursos exercem o controle sobre eles mesmos, uma espécie de metaprocedimento ou metacontrole. A função aqui é a de submeter a dimensão de acontecimento, de acaso dos discursos a partir de princípios de classificação, de ordenação e de distribuição.

Os procedimentos internos analisados por Foucault são o comentário, o autor e a disciplina. Sem me deter no funcionamento destes procedimentos, importa destacar que todos eles atuam na lógica da identidade. O comentário estabelece a identidade do discurso ao apontar o que nele é repetição. $\mathrm{O}$ autor estabelece a identidade entre o discurso e a individualidade $(\mathrm{Eu})$. Por fim, as disciplinas fixam as regras de cada campo do saber, impondo limites e, portanto, a sua definição.

Se a exclusão busca controlar o poder dos discursos e o controle interno objetiva conjurar o seu acontecimento, o terceiro grupo de procedimentos analisados por Foucault procura determinar as condições de seu funcionamento. Ou seja, trata-se de procedimentos que implicam a rarefação dos sujeitos discursivos: quem pode ou não entrar na ordem do discurso. Assim funcionam os rituais, as sociedades de discurso, as doutrinas e as apropriações sociais do discurso.

Mas como pensar a resistência a essa ordem discursiva? Como pensar uma contra-ordem do discurso, sem recair, contudo, nas armadilhas das filosofias do sujeito? O próprio Foucault fala dos posicionamentos de saberes sujeitados, saberes menores, "saberes locais, descontínuos, desqualificados, não legitimados, contra a instância teórica unitária que pretende filtrá-los, hierarquizá-los, ordená-los em nome de um conhecimento verdadeiro [...]"’3.

Michel de Certeau, dialogando com Foucault, reconhece a efetividade das técnicas ordenadoras e disciplinares do discurso. No entanto, propõe-se a interrogar as operações dos usuários com as quais estes inventam seu cotidiano.

Tais operações se dão por meio da fabricação, da produção de uma poética escondida e disseminada entre os sistemas totalitários de produção. A pesquisa de Certeau procura a diferença ou o distanciamento que se estabelece na ordem identitária da representação, do discurso e os usos efetivos que dela fazem os usuários.

Tais operações cotidianas "colocam em jogo uma ratio 'popular', uma

3. Id. Em defesa da sociedade. São Paulo: Martins Fontes, 1999

4. CERTEAU, Michel de. A invenção do cotidiano. 1 . Artes de fazer. Petrópolis: Vozes, 2000. p. 42. maneira de pensar investida numa maneira de agir; uma arte de combinar indissociável de uma arte de utilizar"4.

Essas práticas são táticas que submetem o pesquisador a questões análogas e contrárias à obra de Foucault. Análogas porque tratam das operações situadas no nível micro do poder. Contrárias porque interessa perceber não 
como a disciplina se efetiva, e sim como funcionam "as formas sub-reptícias que são assumidas pela criatividade dispersa, tática e bricoladora dos grupos ou dos indivíduos" , formas que compõem uma rede antidisciplinar.

Entre as táticas observadas por Certeau, interessa-nos aqui a da leitura. Para o autor, há nos leitores uma produção silenciosa. O leitor se apropria do texto do outro para inventar memórias e aí "um mundo diferente (o do leitor) se introduz no lugar do autor" ${ }^{\text {. }}$ Mutação esta que torna o texto habitável, pois "transforma a propriedade do outro em lugar tomado de empréstimo"7. A leitura, portanto, é uma arte que, longe de ser passiva, insinua diferenças no texto que tem força de lei, pois inserido nas estratégias que identificam criação com invenção de linguagens próprias.

\section{A CONTRA-ORDEM DISCURSIVA DAS MINORIAS CONSTITUINTES}

Em uma discussão sobre as minorias, Certeau afirmou que "somente um poder permite tomar a palavra por si mesmo, falá-la por si mesmo"8.

Por sua vez, Muniz Sodré observa que, em Kant, maioridade (Mundigkeit) significa possibilidade de falar. O seu oposto, menoridade (Unmündigkeit), a impossibilidade de falar. Ou seja, a menoridade relaciona-se àquele que não tem voz, que não tem direito à plena fala. A maioridade marca a conquista de ser escutado ou, em outras palavras, de ser cidadão. Daí a noção contemporânea de minoria implicar sua luta para alcançar o poder da fala ${ }^{9}$.

Acontece que é a mídia que nos dias de hoje detém o maior poder de fazer existir socialmente os discursos. Portanto, a cidadania, para as minorias, começa com o acesso democrático aos meios de comunicação. Só assim ela pode dar visibilidade e viabilizar uma outra imagem sua que não a feita pela maioria ${ }^{10}$. $\mathrm{E}$ isto deve ocorrer a partir de uma perspectiva que podemos denominar de constituinte.

O poder constituinte, situa Toni Negri, tem um caráter criativo, originário, liberador e se refere à vontade democrática. Seu paradigma é o de "uma força que irrompe, quebra, interrompe, desfaz todo o equilíbrio preexistente e toda continuidade possível" 11 e se expande. Como as táticas pesquisadas por Certeau, ou como força impulsionadora destas táticas, o poder constituinte "se forma e reforma incessantemente em todo lugar" e configura-se como pluralidade de tempos e espaços ${ }^{12}$.

Sua relação essencial se dá entre criação e multiplicidade, com o trabalho vivo da sociedade que se confronta com o trabalho morto acumulado pelo poder. A afirmação do sujeito constituinte se dá na ruptura com o poder constituído e se estabelece como alternativa a ele.

A discussão que Negri faz a partir de Spinoza também auxilia na definição de minoria constituinte. Em especial, a diferença entre poder (potestas) e potência (potentia). O primeiro é da ordem do constituído, da
5. Ibid., p. 41.

6. Ibid., p. 49.

7. Ibid., p. 49.

8. CERTEAU, Michel de. A cultura no plural. Campinas: Papirus, 1995. p. 147

9. SODRÉ, Muniz. Por um conceito de minoria. In: BARBALHO, A.: PAIVA, R. (Orgs.). Comunicação e cultura das minorias. São Paulo: Paulus, 2005 p. 11-14.

10. A esse respeito, ver: BARBALHO, Alexandre. Cidadania, minorias e mídia: ou algumas questões postas ao liberalismo. In: BARBALHO, A.; PAIVA, R. (Orgs.). Comunicação e cultura das minorias, cit., p. 27-41.

11. NEGRI, Toni. O poder constituinte: ensaio sobre as alternativas da modernidade. Rio de Janeiro: DP\&A, 2002. p. 21.

12. Ibid., p. 21. 
comunicação \& educação • Ano XIV • Número 1 • jan/abr 2009

13. NEGRI, Toni. A anomalia selvagem: poder e potência em Spinoza. Rio de Janeiro: Ed. 34, 1993. p. 249

14. Ibid.

15. Ibid.

16. A esse respeito, ver: BARBALHO, Alexandre.

No ar da diferença: mídia e cultura nas mãos da juventude. Comunicação \& Informação (UFG), v. 9, p. 8-15, 2006.

17. BOURDIEU, Pierre. $O$ que falar quer dizer: a economia das trocas simbólicas. Lisboa: Difel, 1998. p. 99.

18. Segundo dados da Secretaria Estadual de Infra-estrutura, em 2001, a comunidade era composta por 1.071 moradores, sendo que $54,79 \%$ desta população era de jovens com até 25 anos. capacidade de produzir as coisas, e a segunda, da ordem do constituinte, da força que produz as coisas no presente. O poder (potestas) significa "potentia em direção à constituição [...], pois a potência do ser o fixa ou o destrói, o coloca ou o ultrapassa, dentro de um processo de constituição real"13, pois há a "necessidade para a potência de sempre se colocar contra o poder" Potestas só pode ser entendido "como função subordinada à potência do ser elemento - portanto - inteiramente determinado e submetido ao contínuo deslocamento, à continua atualização determinada pelo ser potencial"15. Portanto, poder constituinte é potentia, e só assim pode se manifestar nas minorias.

Podemos definir minoria constituinte, portanto, como aquela que atua de forma criativa e afirma a democracia em sua radicalidade. Ela rompe com o equilíbrio do constituído e expande o universo do possível atuando por meio da potência. A partir desses parâmetros, atua na ordem do discurso, constituindo linhas de fuga, ou seja, produzindo um contradiscurso que traz instabilidade ao ordenamento.

\section{POTÊNCIA CONTRADISCURSIVA DAS MINORIAS CONSTITUINTES: UMA ANÁLISE ESPECÍFICA}

Como ver a atuação das minorias constituintes na ordem discursiva? O que propomos na parte final deste artigo é um exercício de análise de um programa audiovisual, tentando observar o que nos apresenta como elementos constituintes.

Uma premissa fundamental é a de que trataremos a juventude como uma minoria ${ }^{16}$. A partir desse pressuposto, iremos abordar o programa de TV produzido pelo projeto $N o A r$ desenvolvido pela ONG Alpendre. Mas antes da análise propriamente dita do programa televisivo é preciso estabelecer, seguindo as orientações de Pierre Bourdieu, "as relações entre as propriedades do discurso, as propriedades daquele que as pronuncia e as propriedades da instituição que o autoriza a pronunciá-los"17. Para tanto devemos situar o que é e como funciona a ONG (instituição autorizadora do discurso) e, da mesma forma, o programa $N o A r$ (aquele que anuncia o discurso).

O Alpendre, sediado em Fortaleza-CE, atua, entre outras áreas, na formação e produção audiovisual envolvendo jovens de comunidades de baixa renda, em especial os moradores do Poço da Draga, e está situado na beira-mar de Fortaleza $^{18}$. O principal projeto desta linha de ação é o NoAr, um programa audiovisual veiculado na TV pública do Ceará. Com uma hora de duração, é composto de vários quadros que exploram diversos gêneros: documentários, ficções, videoclipes etc.

O NoAr iniciou-se em 2003 e já formou, até 2008, cerca de cem jovens. Durante a execução de cada turma, em torno de dez meses, os selecionados 
recebem uma formação variada, com disciplinas teóricas sobre filosofia, estética, comunicação, cultura e outras, aplicadas à produção audiovisual (roteiro, direção, câmera etc.). As lições são colocadas em prática na constituição de um programa-piloto.

Todas as etapas de elaboração do vídeo são conduzidas por eles, desde a discussão em torno dos temas a serem abordados, passando pela elaboração do roteiro, produção até a etapa da edição. Esse espaço de partilhamento e de solidariedade propiciou que esses jovens criassem entre si uma comunidade de sentidos, de afetos, sinalizando para outras compreensões de política e de cidadania*.

Podemos compreender tais criações como estratégias sensíveis no jogo da comunicação, no sentido que é dado ao termo por Muniz Sodré: "Jogos de vinculação dos atos discursivos às relações de localização e afetação dos sujeitos no interior da linguagem" ${ }^{19}$. Ou seja, além de informação, o NoAr permite o reconhecimento entre subjetividades, não só entre os jovens que o produzem, mas, virtualmente, entre estes e aqueles que assistem ao programa.

Estabelecidas as propriedades daqueles que pronunciam o discurso, bem como da instituição que os autoriza a pronunciá-lo, podemos passar para a análise das propriedades especificamente discursivas. Verificaremos, a seguir, os quadros do primeiro programa que funcionou como uma espécie de programa manifesto, pois expõe os objetivos propostos pelo projeto e suas estratégias sensíveis.

O NoAR, em sua exibição inaugural, compõe-se de sete quadros intercalados por jovens apresentadores. Na primeira parte, o apresentador define o que vai ser tratado: a cidade, a cultura, o conhecimento, a atenção, a pesquisa e a diversidade - temas reunidos em um programa-oficina feito por jovens, para mim e para você, conforme sua proposta.

Colocam-se, assim, os parâmetros aos quais se propõe o $N o A r$, o de ser um discurso constituinte, no sentido dado por Dominique Maingueneau ${ }^{20}$ : o de seu autorreconhecimento, o de possuir uma autoridade própria, pois se trata de um programa-oficina, portanto experimental, inaugurador, e feito por jovens e para jovens, ou seja, que desconhece, ou melhor, não reconhece a ascendência de programas realizados por adultos - o que não implica dizer que o NoAr não seja (in)formado por outras zonas de produção discursiva.

A partir da anunciação do NoAr e, em decorrência, da constituição de uma comunidade discursiva ou de uma comunidade de afetos, os quadros seguintes vão estabelecendo um éthos, um universo de sentidos, uma maneira de dizer que é também uma maneira de ser, através de investimentos na cenografia, no código e no imaginário juvenis.

O primeiro quadro é um videoclipe da música Cangaço. As imagens mostram ruas e casas de bairros pobres, crianças trabalhando ou pedindo esmolas, trabalhadores de várias profissões. A música tem melodia pesada
* Sobre esse assunto, ver: LAGO, Cláudia; LEÃO, Izabel. Revista Viração: um projeto social impresso. Comunicação \& Educação. São Paulo: CCA-ECA-USP/Paulinas, ano XII, n. 3, set./dez. 2007. (N.E.)

19. SODRÉ, Muniz. As estratégias sensíveis: afeto, mídia e política. Petrópolis: Vozes, 2006. p. 10.

20. MAINGUENEAU, Dominique. Cenas da enunciação. Curitiba: Criar, 2006. p. 49. 
e a letra trata da situação de miséria e violência do Nordeste na época do cangaço.

Para a apresentação do quadro seguinte, Ações Urbanas, a apresentadora informa que se trata de coisas que normalmente nós não fazemos. No caso, o registro de uma intervenção artística e urbana realizada por garotos e garotas do projeto e jovens artistas da cidade. A intervenção se constitui da ocupação da calçada do Passeio Público, elegante praça construída no final do século XIX e que nos dias de hoje é frequentada por prostitutas, travestis, mendigos e sem-tetos que habitam o centro da cidade.

No registro citado, cada integrante levou uma cadeira e sentou-se de costas para a rua e de frente para os jardins gradeados da praça. Postos um ao lado do outro, ficavam conversando entre si e com os transeuntes curiosos. O vídeo mostra essas imagens, intercaladas com entrevistas realizadas com os passantes e suas impressões sobre o que estava acontecendo.

$\mathrm{Na}$ apresentação do terceiro quadro, um jovem informa: "Uma ONG é idealizada por pessoas que exercem sua cidadania de forma direta e autônoma, voltando-se para interesses coletivos e diferenciando-se da lógica do mercado [...]. Encontramos formas em tudo que é comunicação".

O quadro se dedica a mostrar trabalhos de outras ONGs. No caso desse programa, o documentário tratou do "III Encontrarte - Encontro da rede de arte e educação do Ceará”, que reuniu durante três dias mais de trezentos jovens de várias cidades e organizações cearenses.

A quarta apresentadora situa o próximo quadro, o de Clip-Haicai: "Alma da poesia, leveza de um ser, resgate de memórias. Clip não explicado, mas entendido, fruto de intuição. Interno, desprazeroso, banal. Suavizando a sociedade fechada da realidade de seu tempo duro".

O clipe tem como tema a cidade, tanto nas imagens quanto nos versos.

O quinto apresentador nos exibe o quadro seguinte, Pessoas Anônimas. O documentário é sobre dona Alzira, uma senhora que vive sozinha em um barraco construído em um píer abandonado que faz parte do Poço da Draga.

O sexto apresentador situa outro quadro, que, como o terceiro, relaciona o NoAr com outras experiências e políticas culturais juvenis, ao veicular a produção audiovisual de jovens atuantes em outras ONGs: "Uma nova forma de olhar. Mostrar e possibilitar uma nova linguagem de ver o mundo. Vídeos autorais, com olhares críticos, criativos e observadores, que não se detêm ao tradicional".

O vídeo apresentado foi Carne e oficina, realizado com os jovens participantes do projeto Imagens da Paz, desenvolvido pela ONG Fábrica de Imagens. Trata-se de um videopoema que expõe as contradições da vida cotidiana em uma grande cidade.

O sétimo apresentador define o último quadro, Contemporando, que encerra o NoAr: um vídeo realizado com câmera fixa, mostrando parte de uma praça onde se destaca um homem idoso sentado no banco, de costas para o telespectador, que observa os transeuntes. 
O que nos diz, portanto, a veiculação inaugural do NoAr? Em primeiro lugar, afirma a criatividade dos jovens realizadores; a vontade de produzirem suas próprias imagens sobre a cidade e atentos à diversidade. A ideia de programa-oficina alinha a proposta do programa com a inventividade, com a tentativa de rompimento em relação às gramáticas audiovisuais estabelecidas.

Alguns dos quadros revelam mais sobre o caráter inovador do $\mathrm{NoAr}$, como o Ações Urbanas, o Contemparando e o Clip-Haicai.

O primeiro provoca um estranhamento no telespectador pela forma como a cidade é apropriada através da intervenção artística. No segundo, o recorte não-usual da cidade revela um espaço e um tempo outros, no Mesmo; uma diferença na experiência e na representação hegemônica do espaço urbano. Essa mesma sensação predomina no Clip-Haicai, em que versos e imagens compõem uma poética da cidade que poderíamos denominar de entre-lugar, no sentido estabelecido por Homi Bhabha, de processos de articulação da diferença que propiciam estratégias de subjetivação ${ }^{21}$.

Outra afirmação que nos vem dos quadros apresentados pelo NoAr é o jogo de desterritorialização e reterritorialização. Com exceção do quadro sobre o encontro de arte-educação, todos os outros foram gravados em Fortaleza, mas não há nenhuma referência explícita à cidade, que poderia ser qualquer metrópole brasileira.

Mas, se há uma perda de identidade com a cidade, há uma reterritorialização afetiva e crítica a partir dos espaços habitados e de experiências dos jovens, uma reterritorialização que não é da ordem da identidade, mas da diferença, ou da identificação. É dona Alzira em seu barraco no píer, são os transeuntes nas ruas, calçadas e praças do centro comercial, dos bairros pobres.

Por fim, destacaríamos na organização do NoAr sua relação com as experiências de outras ONGs, seja documentando essas atuações, como no terceiro quadro, seja abrindo espaço na programação (e no horário de uma televisão pública) para exibir trabalhos realizados por jovens de outras organizações não-governamentais. Longe da lógica da concorrência, estabelece-se aqui um espaço de compartilhamento, de solidariedade, de amizade. Ou de rede, característica dos novos movimentos sociais.

\section{CONSIDERAÇÕES FINAIS}

Nas considerações anteriores, analisamos como o NoAr se coloca como um programa criativo, no interior da gramática audiovisual estabelecida. É claro que não rompe totalmente com esta gramática, pois, em última instância, se isso acontecesse, o programa não poderia ser consumido. Como demonstra Stuart Hall, para que o processo de codificação/decodificação se efetive, é necessário que o sentido seja apreendido. Caso contrário, não
21. BHABHA, Homi. O local da cultura. Belo Horizonte: UFMG, 2005. 
havendo sentido, o discurso não se articula em práticas sociais e, por sua vez, não produz efeito ${ }^{22}$.

Podemos entender esse programa-manifesto como um discurso constituinte, na medida em que funciona como um rito de instituição, na definição de Bourdieu ${ }^{23}$. Ou seja, ele estabelece um limite onde atua e o modo como atua: trata-se, como expõe o jovem apresentador, de um programa-oficina, portanto, que não tem a obrigação de acertar, mas de inventar, de questionar, de arriscar.

Mas, acima de tudo, a força constituinte do projeto está no processo de feitura do $\mathrm{NoAr}$, quando se estabelece entre os jovens uma comunidade de sentido e de afetos, no convívio entre eles que, a todo momento, exige a relação com o outro. Temos aqui uma política da amizade que se exerce pressionando os limites da política, da cidadania, enfim, da democracia ${ }^{24}$.

As interações (sociais, afetivas, simbólicas) que aconteceram ao longo dos meses entre esses jovens resultaram na produção de subjetividades singulares, com todas as suas contradições e ambiguidades. Uma outra possibilidade de subjetivação que não aquelas modalidades massificadas, mas uma subjetividade processual e singularizante.

Portanto, podemos apontar que a eficácia do projeto NoAr é a da experimentação feita por jovens e para jovens atentos à pesquisa e à diversidade, instaurando práticas e discursos heterodoxos que instituem e consagram a diferença e a produção de subjetividades singulares entre jovens de bairros pobres de Fortaleza.

\section{REFERÊNCIAS BIBLIOGRÁFICAS}

BARBALHO, Alexandre. Cidadania, minorias e mídia: ou algumas questões postas ao liberalismo. In: BARBALHO, A.; PAIVA, R. (Orgs.). Comunicação e cultura das minorias. São Paulo: Paulus, 2005.

. No ar da diferença: mídia e cultura nas mãos da juventude. Comunicação \& Informação (UFG), v. 9, 2006.

BHABHA, Homi. O local da cultura. Belo Horizonte: UFMG, 2005.

BOURDIEU, Pierre. O que falar quer dizer: a economia das trocas simbólicas. Lisboa: Difel, 1998.

22. HALL, Stuart. Da diáspora: identidades e mediações culturais. Belo Horizonte: UFMG, 2003.

23. BOURDIEU, Pierre. O que falar quer dizer, cit.

24. ORTEGA, Francisco. Para uma política da amizade: Arendt, Derrida, Foucault. Rio de Janeiro: Relume Dumará, 2000.
CERTEAU, Michel de. A cultura no plural. Campinas: Papirus, 1995.

. A invenção do cotidiano. 1. Artes de fazer. Petrópolis: Vozes, 2000.

FOUCAULT, Michel. A arqueologia do saber. Rio de Janeiro: Forense Universitária, 2002.

. A ordem do discurso. São Paulo: Loyola, 1998.

. Em defesa da sociedade. São Paulo: Martins Fontes, 1999. 
HALL, Stuart. Da diáspora: identidades e mediações culturais. Belo Horizonte: UFMG, 2003.

LAGO, Cláudia; LEÃO, Izabel. Revista Viração: um projeto social impresso. Comunicação \& Educação. São Paulo: CCA-ECA-USP/Paulinas, ano XII, n. 3, set./ dez. 2007.

MAINGUENEAU, Dominique. Cenas da enunciação. Curitiba: Criar, 2006.

NEGRI, Toni. A anomalia selvagem: poder e potência em Spinoza. Rio de Janeiro: Ed. 34, 1993.

O poder constituinte: ensaio sobre as alternativas da modernidade. Rio de Janeiro: DP\&A, 2002.

ORTEGA, Francisco. Para uma política da amizade: Arendt, Derrida, Foucault. Rio de Janeiro: Relume Dumará, 2000.

SODRÉ, Muniz. As estratégias sensíveis: afeto, mídia e política. Petrópolis: Vozes, 2006.

Por um conceito de minoria. In: BARBALHO, A.; PAIVA, R. (Orgs.). Comunicação e cultura das minorias. São Paulo: Paulus, 2005. 


\title{
Por um ensino democrático e prático, comprometido com a formação para a cidadania
}

\begin{abstract}
Abrir um espaço amplo e plural para discussão e reflexão sobre estudos apresentados por educadores e pesquisadores da área da Educação. Com esse intuito, a coleção Educação em Foco quer contribuir não só para a democratização do ensino, mas também buscar práticas e propostas inovadoras a fim de que a Educação possa desempenhar uma de suas funções mais importantes: a formação para a cidadania.
\end{abstract}

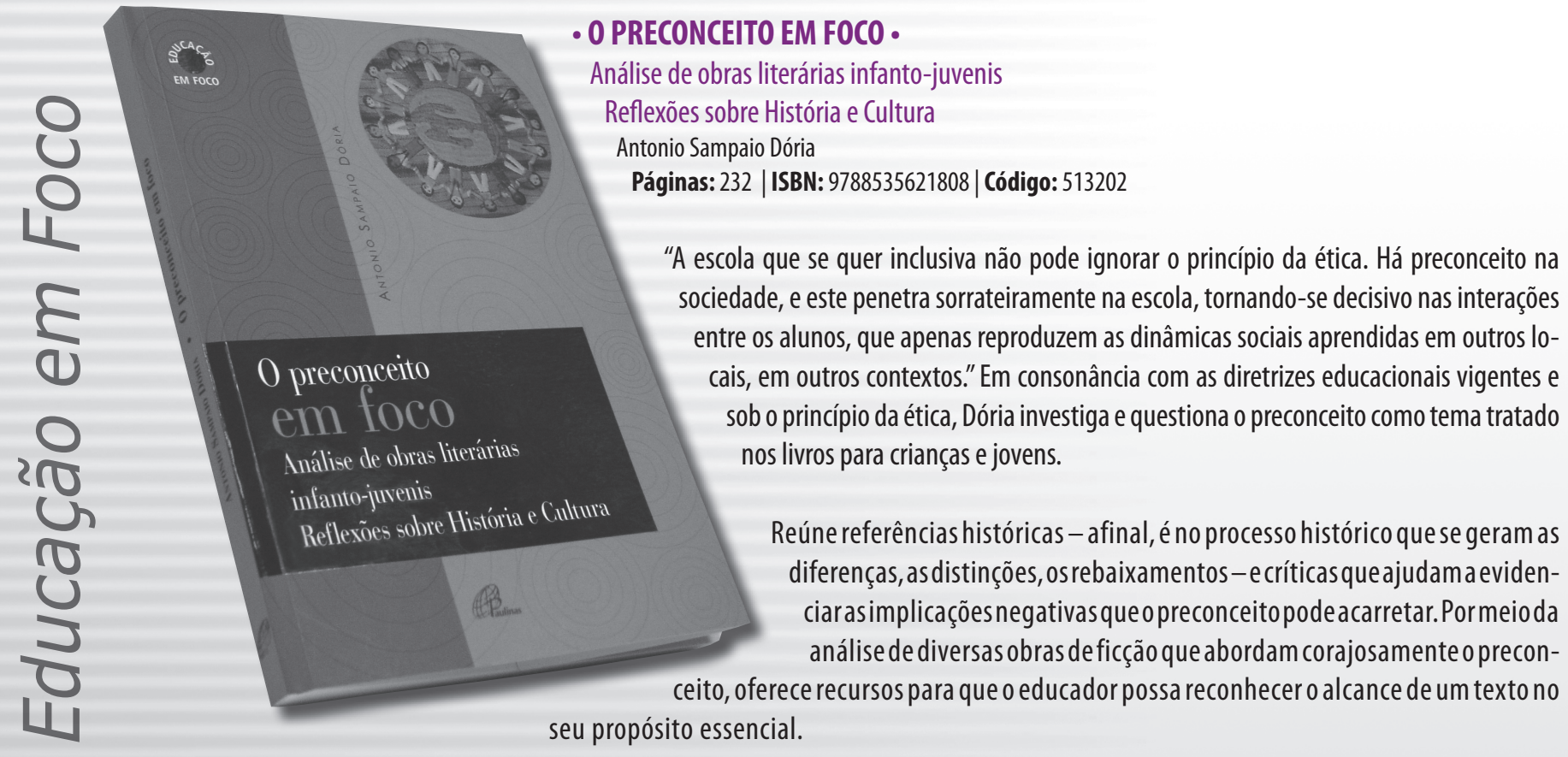

"O livro, como signo, nunca é um instrumento neutro no processo social, e torna-se particularmente relevante quando há uma discussão de valores em curso." Sem indicar uma fórmula, 0 autor aponta caminhos através de textos ficcionais que abordam o tema para que o professor possa também fazer uso dele em sala de aula, pois trazem em sua fabulação o sentimento e 0 sabor da experiência.

Leia também

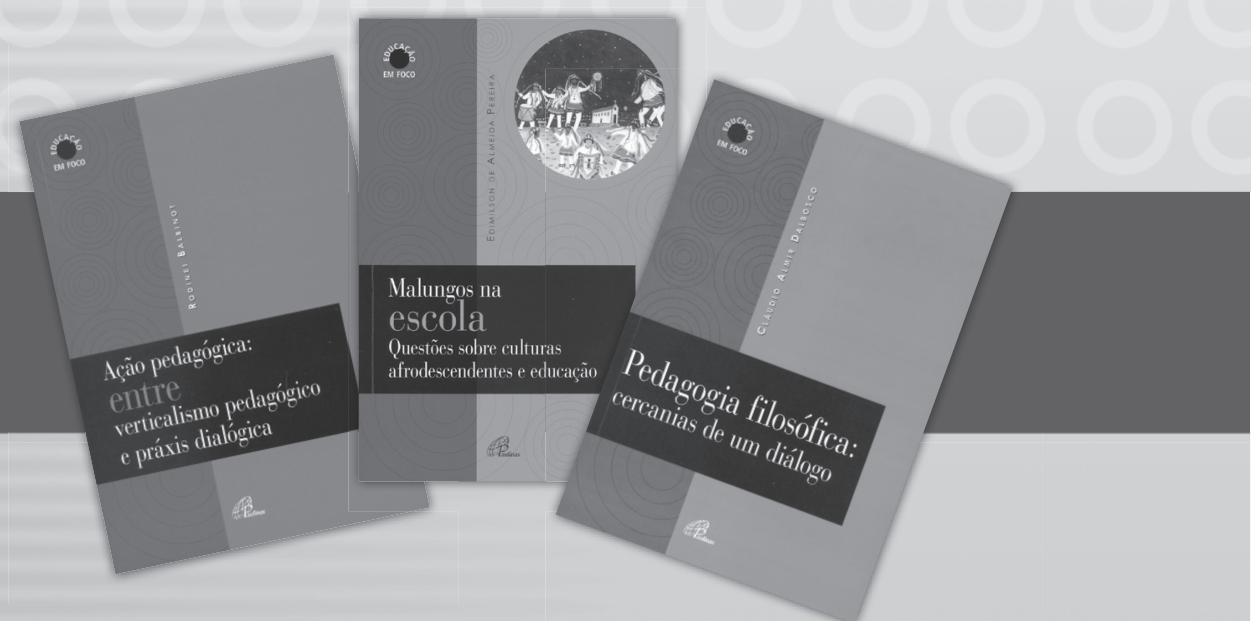

À venda na Rede Paulinas de Livrarias Se preferir, ligue 08007010081 ou acesse www.paulinas.org.br 